\title{
The effect of post-exercise caffeine and chlorogenic acid supplementation on blood glucose disposal and insulin sensitivity
}

\author{
Jason R Beam", Ann L Gibson ${ }^{1}$, Chad M Kerksick', Carole A Conn², Ailish C White ${ }^{1}$, Christine M Mermier ${ }^{1}$ \\ From International Society of Sports Nutrition: 10th Annual ISSN Conference and Expo \\ Colorado Springs, CO, USA. 14-15 June 2013
}

\begin{abstract}
Background
Caffeine and chlorogenic acid are two compounds in green coffee beans that alter blood glucose disposal and insulin sensitivity. Caffeine has been shown to decrease glucose disposal and insulin sensitivity when taken 60 minutes prior to an oral glucose tolerance test in humans, whereas chlorogenic acid has been shown to increase glucose disposal and insulin sensitivity in humans. The purpose of this study was to investigate the effect of ingesting caffeine with dextrose or chlorogenic acid with dextrose immediately after an exhaustive bout of cycling on blood glucose and insulin disposal when compared to ingesting dextrose alone.
\end{abstract}

\section{Methods}

Ten moderately to highly trained male cyclists $(26 \pm 5$ years; $179.9 \pm 5.4 \mathrm{~cm} ; 77.6 \pm 13.3 \mathrm{~kg}$; BMI: $24.0 \pm 4.3 \mathrm{~kg} \cdot \mathrm{m}^{-2} ; \mathrm{VO}_{2}$ peak: $55.9 \pm 8.4 \mathrm{ml} \cdot \mathrm{kg}^{-1} \cdot \mathrm{min}^{-1}$ ) participated in this study. Each participant completed three experimental trials in random order the morning after abstaining from food, caffeine, and chlorogenic acid supplements for 12 hours. Each trial consisted of a 30-minute high intensity bout of cycling at $60 \%$ of peak power output ( $90 \% \mathrm{HR}$ max). Immediately after the exercise, each participant consumed $5 \mathrm{mg} \cdot \mathrm{kg}^{-1}$ body weight of caffeine plus $75 \mathrm{~g}$ of dextrose (CAF), $5 \mathrm{mg} \cdot \mathrm{kg}^{-1}$ body weight of chlorogenic acid plus $75 \mathrm{~g}$ of dextrose (CGA), or $5 \mathrm{mg} \cdot \mathrm{kg}^{-1}$ body weight of dextrose plus $75 \mathrm{~g}$ dextrose (PLA). Blood was drawn to measure glucose and insulin immediately before exercise, immediately after exercise, every 15 minutes during the first hour of passive recovery, and every 30 minutes during the second hour of recovery. The blood glucose and

${ }^{1}$ Department of Health, Exercise, and Sports Sciences, University of New Mexico, Albuquerque, NM 87131, USA

Full list of author information is available at the end of the article insulin area under the curve (AUC) and Matsuda insulin sensitivity index (ISI) were calculated for each trial. Data were analyzed using ANOVAs with repeated measures and Pearson correlations $(\alpha=.05)$.

\section{Results}

There were no significant time-by-treatment effects for blood glucose and insulin. The two-hour glucose and insulin AUCs, respectively, for the CAF $(658 \pm 74 \mathrm{mmol} / \mathrm{L}$ and $30,005 \pm 13,304 \mathrm{pmol} / \mathrm{L}), \mathrm{CGA}(637 \pm 100 \mathrm{mmol} / \mathrm{L}$ and $31,965 \pm 23,586 \mathrm{pmol} / \mathrm{L})$, and PLA $(661 \pm 77 \mathrm{mmol} / \mathrm{L}$ and $27,020 \pm 12,339 \mathrm{pmol} / \mathrm{L})$ trials were similar $(\mathrm{p}>.05)$. The ISI for the CAF (9.7 \pm 5.2$)$, CGA (12.1 \pm 7.9 ), and PLA (10.0 \pm 7.3$)$ trials were also not significantly different $(\mathrm{p}>.05)$. There was substantial inter-subject variability in glucose and insulin responses during the three trials; this likely contributed to the non-significant findings. Body mass index was highly related to insulin AUC for the CAF $(r=.71)$, CGA $(r=.80)$, and PLA ( $\mathrm{r}=.73$ ) trials. Relative $\mathrm{VO}_{2}$ peak was inversely and moderately-to-highly related to insulin AUC for the CAF $(\mathrm{r}=-.82)$, CGA $(\mathrm{r}=-.63)$, and PLA $(\mathrm{r}=-.63)$ trials.

\section{Conclusion}

Caffeine and chlorogenic acid may affect the body's ability to regulate post-exercise insulin-mediated glucose transport into the exercised skeletal muscle through different mechanisms; however more research is warranted to verify this hypothesis. The heterogeneity of our sample highlights the inter-individual variability in post-exertional response to caffeine and chlorogenic acid when dosage is based on body weight. Consequently, we recommend that future investigations of glucose tolerance and insulin sensitivity utilize a sample that is homogenous in body composition and training status. 


\section{Authors' details}

'Department of Health, Exercise, and Sports Sciences, University of New Mexico, Albuquerque, NM 87131, USA. ${ }^{2}$ Department of Individual, Family, and Community Education, University of New Mexico, Albuquerque, NM

87131, USA.

Published: 6 December 2013

doi:10.1186/1550-2783-10-S1-P2

Cite this article as: Beam et al:: The effect of post-exercise caffeine and chlorogenic acid supplementation on blood glucose disposal and insulin sensitivity. Journal of the International Society of Sports Nutrition 2013

10(Suppl 1):P2.

Submit your next manuscript to BioMed Central and take full advantage of:

- Convenient online submission

- Thorough peer review

- No space constraints or color figure charges

- Immediate publication on acceptance

- Inclusion in PubMed, CAS, Scopus and Google Scholar

- Research which is freely available for redistribution

Submit your manuscript at www.biomedcentral.com/submit 